\title{
ANÁLISE DE CLARIFICAÇÃO DE EFLUENTES INDUSTRIAIS UTILIZANDO GERADOR ELETRÔNICO DE OZÔNIO
}

\author{
W. MAIDANA ${ }^{1}$, C. KREUTZ ${ }^{2}$ e R. BERNARDI $I^{3}$ \\ ${ }^{1}$ Universidade Tecnológica Federal do Paraná, Departamento de Engenharia Eletrônica. \\ ${ }^{2}$ Universidade Tecnológica Federal do Paraná, Departamento de Engenharia Ambiental \\ E-mail para contato: wellington-maidana@ hotmail.com
}

\begin{abstract}
RESUMO - O presente trabalho apresenta uma análise da clarificação de efluentes resultantes de dois setores industriais: a indústria têxtil e frigorífica, utilizando ozônio que é uma alternativa que não agride a saúde humana e está presente na natureza, também possível de ser gerado através de um sistema eletrônico. Para obter os resultados apresentados neste trabalho utilizando os efluentes têxteis e de frigorifico foram separados em alíquotas de $100 \mathrm{ml}$. Os dois efluentes foram submetidos ao tratamento utilizando ozônio em um intervalo de tempo que variou de 60 a 540 segundos, sendo visível a ação de clarificação do ozônio nos testes realizados com estes efluentes.
\end{abstract}

\section{INTRODUÇÃO}

\section{1. Água}

A água é um patrimônio da humanidade, um elemento visto antes como inesgotável sendo vital para todos os ecossistemas e sociedades humanas, devendo ser compartilhada com as gerações atuais e futuras que habitam as bacias hidrográficas e suas fronteiras.

No Brasil, através da Lei Federal No 9433, de 08.01.1997 que estabelece a Política Nacional de Recursos Hídricos, a água passa a ser reconhecida como um recurso natural limitado e dotado de valor econômico.

Um dos principais problemas que surgiram neste século foi a crescente contaminação dos recursos hídricos. A água sempre foi utilizada para nosso benefício uma vez que, com boa qualidade e suficiência gera riquezas, desenvolvimento e propicia vida saudável. Com o crescimento das cidades e a Revolução Industrial houve um aumento considerável do seu consumo o que levou a uma preocupação universal em se evitar episódios de contaminação ambiental com este bem natural. 


\section{9 a 22 de outubro de 2014 \\ Florianópolis/SC}

\subsection{Efluente Têxtil}

Desde o inicio das civilizações há relatos da utilização de corantes. Os corantes sintéticos são extensivamente utilizados na indústria têxtil, gráfica, fotográfica e como aditivos em derivados de petróleo, existem aproximadamente 10.000 tipos diferentes corantes e pigmentos que são usados na indústria.

O setor têxtil possui um destaque especial, já que seu grande parque industrial instalado pode produzir grandes volumes de efluentes, se não tratados corretamente, podem gerar sérios impactos ambientais. A indústria têxtil possui efluentes altamente coloridos, devido ao corante utilizado no tingimento, o que não se fixa na fibra durante o processo acaba sendo descartado (LIN e LIN 1993).

As indústrias têxteis e as lavanderias têm a água como um de seus principais insumos, utilizada em grandes volumes. Estima-se que, para produzir $1 \mathrm{~kg}$ de tecido, sejam necessários 80 L de água.Com a tendência de crescimento das duas atividades, a captação também deverá aumentar. Pesquisa da ABIT - Associação Brasileira da Indústria Têxtil e de Confecção apontou alta de 16,5\% ao ano, em média, entre 2006 e 2010. Segundo a entidade, existem hoje no país 23 empresas de fibras, 4725 indústrias têxteis e 26176 confecções. Já o último levantamento da ANEL - Associação Nacional das Empresas de Lavanderia, de 2009, mostrou faturamento anual de mais de $\mathrm{R} \$ 2,5$ bilhões e previsão de $25 \%$ de crescimento para os cinco anos seguintes. Como não é possível eliminar o uso da água na cadeia produtiva, muitas empresas estão investindo em estações de tratamento com finalidade de reuso (REZENDE 2012). Nos processos das indústrias têxteis e lavanderias, grande parte da água consumida não é incorporada ao produto final e cerca de $80 \%$ se torna efluente altamente heterogêneo e poluente.

Atualmente, as indústrias têm utilizado seus tratamentos baseados em processos físicos e biológicos que, apesar de apresentarem certa eficiência na remediação de efluentes, apresentam inúmeras limitações.

\subsection{Efluentes Líquidos de Frigoríficos}

No setor alimentício os aspectos e impactos ambientais dos frigoríficos e matadouros estão totalmente ligados ao alto consumo de água e à geração de efluentes líquidos com alta carga poluidora. Segundo a CETESB (Companhia de Tecnologia de Saneamento Ambiental do Estado de São Paulo), cerca de 80 a $90 \%$ da água consumida durante o processo de produção e abate nos frigoríficos é descarregado como efluentes líquidos com alta carga orgânica e resíduos sólidos. Um ponto importante é que esses efluentes gerados possuem altos valores de DBO (Demanda Bioquímica de Oxigênio) e DQO (Demanda Química de Oxigênio) parâmetros utilizados para quantificar carga poluidora orgânica nos efluentes. Ressalta ainda que o sangue tem a DQO mais alta de todos os efluentes líquidos gerados no processamento de carnes. Sangue líquido bruto tem uma DQO em torno de 400g/l, uma DBO de aproximadamente $200 \mathrm{~g} / \mathrm{l}$ e uma concentração de nitrogênio de cerca de $30 \mathrm{~g} / \mathrm{l}$.

Esta preocupação na geração de efluentes em larga escala tem impulsionado as indústrias a práticas do reuso da água tratada que corresponde aos padrões sanitários para ser reinserida novamente no processo industrial. 


\section{9 a 22 de outubro de 2014 \\ Florianópolis/SC}

\subsection{O Ozônio}

O Ozônio, que é um elemento composto por três átomos de oxigênios, esta presente na estratosfera e é responsável por agir como filtro dos raios ultravioleta que são emitidos pelas radiações solares (Amorim 2004). Ele também é um poderoso oxidante, bactericida e desinfetante que purifica a atmosfera. Uma das principais vantagens de se utilizar o ozônio como agente oxidante é que não há produção de resíduos nocivos à saúde humana, pois sua ação oxidante produz como subproduto apenas oxigênio (Souza,2006).

O ozônio reage facilmente com a maior parte dos corantes utilizados nas indústrias têxteis. De maneira geral, o ozônio apresenta características biocidas, eliminando bactérias, vírus, matéria orgânica e microorganismos. Em geral, tem eficiência maior que o cloro e, uma vez diluído em água, não deixa subprodutos (Bonaldo, 2010). Os benefícios técnicos se juntam aos benefícios econômicos. Uma vez implementado, o tratamento utilizando ozônio, se mostra mais barato para se operar do que o método com cloro (BISPO \& FLAIBAM apud ARAUJO et. al, 2012).

A produção do ozônio utilizando o gerador de ozônio ocorre através do "processo corona", o qual consiste em aplicar uma descarga elétrica em um fluxo de ar ou oxigênio. De difícil transporte e armazenamento, o ozônio é produzido próximo ao local a ser utilizado (Di Bernardo,1993). As descargas elétricas quebram a molécula de $\mathrm{O}_{2}$, permitindo a recombinação em $\mathrm{O}_{3}$. A reação ocorre em um reator composto por dois tubos metálicos concêntricos e um tubo de vidro utilizado como dielétrico. A atuação do reator pode ocorrer através da alimentação de um transformador elevador de tensão, conectado diretamente à rede. Porém, a baixa freqüência com que a rede opera torna esta opção pouco viável, pois o transformador se torna grande e pesado. Além disto, a descarga seria mantida por um tempo relativamente longo, podendo causar avarias à célula devido ao superaquecimento ( Bonaldo, 2010 ). Atualmente existem vários circuitos eletrônicos de potência que torna possível o funcionamento do reator com maior eficiência.

\section{OBJETIVOS}

Buscando uma alternativa para solucionar um dos principais problemas que afligem a nossa sociedade, a poluição dos leitos dos rios com efluentes que podem agredir a natureza, afetar a saúde e a qualidade da humanidade. Este trabalho visa demonstrar a eficiência do processo de clarificação de efluentes de processos industriais através do tratamento com ozônio e propor levantamento de estudos sobre possível desinfecção destes efluentes através do processo de ozonização.

\section{MATERIAIS E MÉTODOS}

\subsection{O Sistema Utilizado}

Para a realização dos testes foi necessário utilizar um reator construído com uma mangueira transparente com um dispersor (pedra porosa de aquário) no seu interior por onde o ozônio é injetado. Conforme pode ser visto na figura 2. 


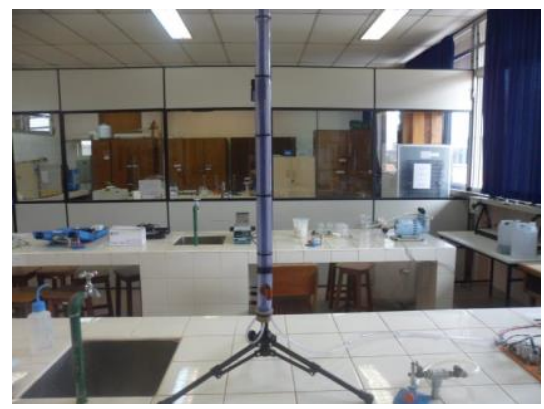

Figura 2 - Reator.

O equipamento utilizado para a produção de ozônio (SCHIAVON, 2012), conforme a figura 3, possui duas células geradoras de ozônio de modo a garantir $1,2 \mathrm{~g} \mathrm{O}_{3} / \mathrm{h}$ a uma vazão de $9 \mathrm{~L} / \mathrm{min}$ de ar.

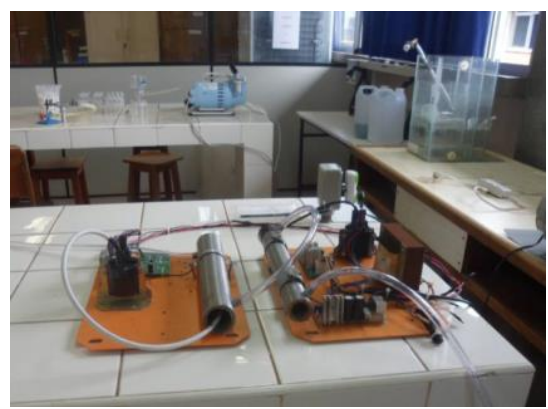

Figura 3 - Gerador de Ozônio.

O fluxo de ar com vazão de $9 \mathrm{~L} / \mathrm{min}$ foi gerado com o auxílio de um compressor de ar e um fluxômetro. A figura 4 mostra o sistema completo utilizado nos testes.

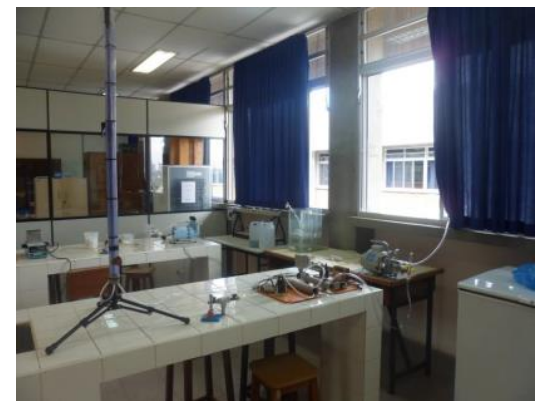

Figura 4 - Sistema completo utilizado para os testes.

\subsection{Efluentes Utilizados}

\subsubsection{Efluente têxtil}

Preparou-se para os testes preliminares uma mistura contendo água com corante para tecido (Tingecor - Guarani) na cor vermelha para simular um efluente têxtil. Tal mistura pode ser vista na figura 5 . 


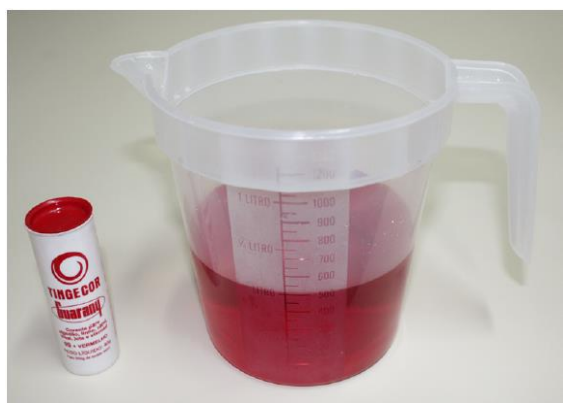

Figura 5 - Efluente Têxtil.

\subsubsection{Efluente de Frigorifico}

Para realização dos testes utilizando efluentes de frigorifico, foi feita a coleta deste efluente em um frigorifico da região de Campo Mourão - PR.

$\mathrm{O}$ efluente que foi utilizado passa por um pré-tratamento. Na figura 6 mostra a fase inicial do pré-tratamento, nesta fase é retirado parte dos resíduos sólidos presentes no efluente assim que retirado do frigorifico.

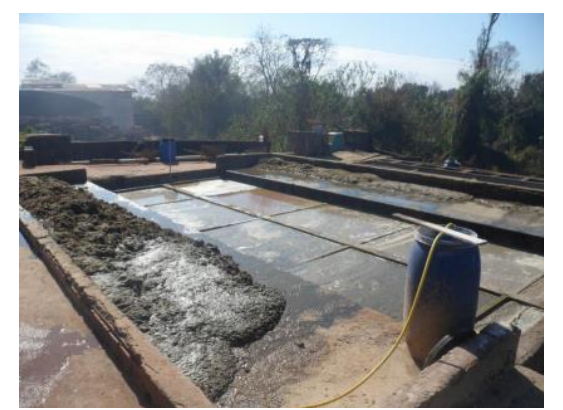

Figura 6 - Efluente primário retirado do frigorifico.

Após a retirada de parte dos resíduos sólidos presentes o efluente é direcionado a uma lagoa (Figura 7) onde se deposita este efluente.

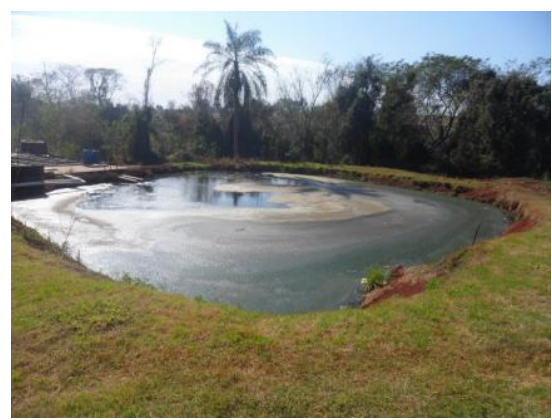

Figura 7 - Lagoa com Efluente. 
Em seguida o efluente passa para outra lagoa onde é acrescentado óxido de cálcio e acionadas algumas bombas que ajudam no processo de oxigenação, eliminação do odor e algumas substâncias presentes no efluente.

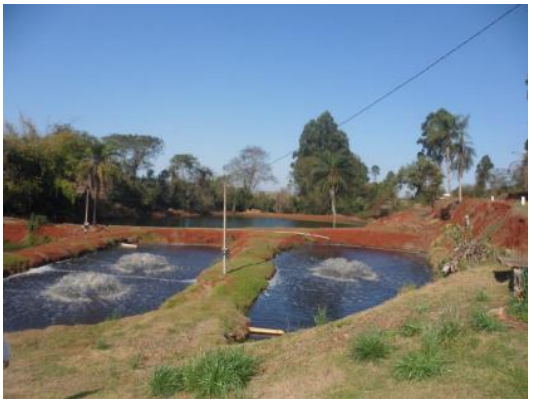

Figura 8 - Lagoa onde se realiza tratamento com óxido de cálcio.

A figura 9 mostra o local onde foi coletado o efluente do frigorifico para o tratamento com ozônio. O efluente contido nesta lagoa é, hoje, descartado em um rio próximo ao frigorifico.

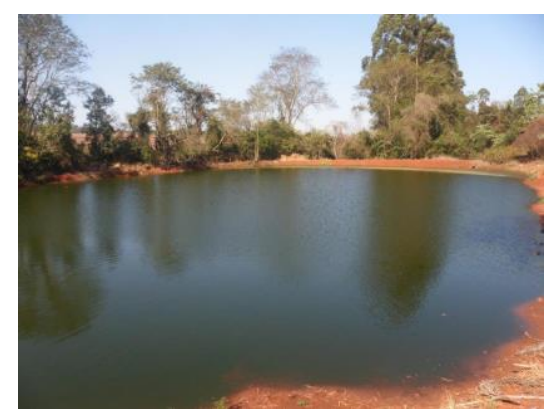

Figura 9 - Lagoa onde fora retiradas as amostra de efluente para o tratamento com ozônio.

\subsection{Metodologia}

A realização dos testes ocorreu da seguinte forma:

Os efluentes têxteis e de frigorifico foram separados em alíquotas de $100 \mathrm{ml}$. O efluente têxtil foi submetido ao tratamento utilizando ozônio no intervalo de tempo de 60 a 120 segundos. Já o efluente coletado na lagoa do frigorifico foi submetido a testes nos intervalos de 180 a 540 segundos.

Para os testes, como já foi citado, usou-se um compressor de ar com o fluxômetro regulado para uma vazão de $9 \mathrm{~L} / \mathrm{s}$.O fluxômetro estava conectado em um tubo que injetava ar na célula de geração de ozônio. O gerador de ozônio foi alimentado por uma tensão de 127 Volts por aproximadamente 15 segundos até estabilizar a geração de ozônio. Após esse tempo o gerador era conectado ao reator, injetando ozônio no efluente. Após passar pela ozonização o efluente foi armazenado em recipientes para visualização dos resultados. 


\section{RESULTADOS DA PESQUISA E DISCUSSÃO}

\subsection{Análise com Efluente Têxtil}

Para a análise com efluente têxtil foram realizados testes nos seguintes intervalos de tempo: 60, 70, 80, 90, 100, 110 e 120 segundos. Sendo possível visualizar na figura 10 os resultados obtidos através do tratamento com ozônio em cada amostra.

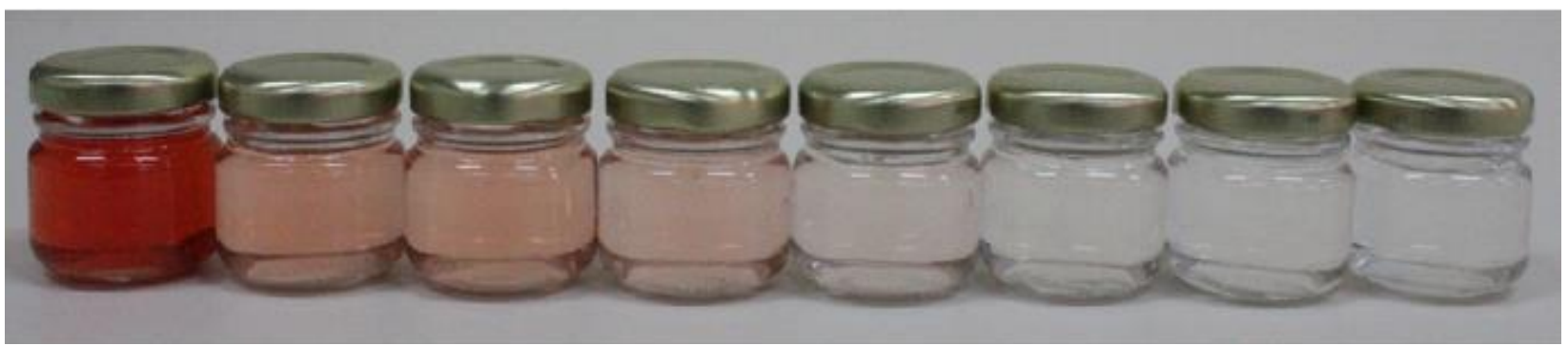

Figura 10 - Resultados obtidos através do tratamento com ozônio.

Cada amostra de $100 \mathrm{ml}$ de efluente sofreu injeção de ozônio em intervalos diferentes de tempos. Da esquerda para a direita tem-se: amostra inicial, após 60s, 70s, 80s, 90s, 100s, 110s, 120s. Os frascos estão organizados de forma conforme o tempo no qual foram submetidos ao tratamento, sendo o primeiro frasco o efluente não tratado e o último, o efluente que recebeu maior quantidade de ozônio.

\subsection{Análise com Efluente de Frigorifico}

Primeiramente utilizou-se o efluente em um teste para determinar quanto tempo o efluente clarifica com o tratamento com ozônio, utilizou-se $100 \mathrm{ml}$ em um teste de 600 segundos. Observando que após 540 segundos o efluente já adquire uma boa claridade, foi realizado testes nos seguintes intervalos: 180, 360 e 540 segundos.

Os resultados obtidos estão presentes na figura 11, sendo o primeiro frasco a amostra retirada da lagoa apresentada na figura 9.

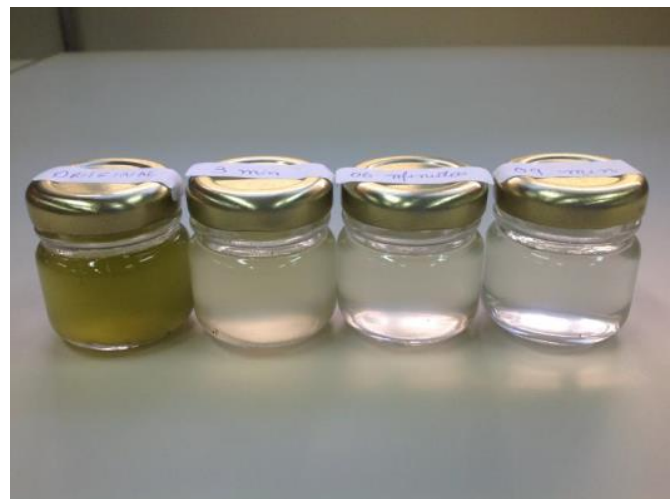

Figura 11 - Efluentes de frigorífico tratados com ozônio. Cada amostra de $100 \mathrm{ml}$ recebeu ozônio nos 
tempos de, da esquerda para a direita, 180, 360 e 540 segundos sendo que a primeira amostra é do efluente não tratado.

\section{DISCUSSÃO E CONCLUSÃO}

Embora trate-se de resultados preliminares, pode-se observar através dos testes realizados que o ozônio age com eficiência na clarificação dos dois efluentes analisados. Para garantir que os resultados não passam de um mero efeito visual será preciso caracterizar física, química e biologicamente o que resultou desse processo de clarificação para podermos verificar a real eficiência do ozônio, também, no processo de tratamento desses efluentes.

\section{REFERÊNCIAS}

AMORIM, Alexsandra de; LARA, Moisés da Silva O que é Ozônio? 2004 Disponível em: <http://bohr.quimica.ufpr.br/ dallara/camada.html>. Acesso em16/07/ 2013.

Associação Brasileira de Normas Técnicas (ABNT). ISO 14.001:2004. Sistema de gestão ambiental: requisitos com orientações para uso. Disponível em <http://www.abntcatalogo.com.br/norma.aspx?ID=1547. > Acesso em : 11/08/2013.

BONALDO, J. P. Conversores para alimentação de células geradoras de ozônio. Dissertação de Mestrado -- Campinas, SP: [s.n.], 2010.

DI BERNARDO, L. Métodos e técnicas de tratamento de água. Rio de Janeiro : ABES, 1993. v.2

LIN, S. H. e LIN, C. M. Treatment of Textile Waste Effluents by Ozonation and Chemical Coagulation. Water Research. v.27, n.12, p.1743-1748, 1993.

MINISTÉRIO DO MEIO AMBIENTE / CONSELHO NACIONAL DE RECURSOS HÍDRICOS. Resolução No 54, de 28 de nov. 2005. Diário Oficial da União. Brasília, 09 mar. 2006.

RESENDE, Letícia Passos. Reuso na indústria têxtil e lavanderias. Revista Hydro, São Paulo, ano 6, n.66, p.14-19, abr. 2012. Disponível em: <http://sindlav.com.br/wpcontent/uploads/2012/05/H66-Especial.pdf> Acesso em: 15/07/2013

SCHIAVON, G. J. Modelagem, desenvolvimento e análise de um sistema gerador de ozônio, operando em alta frequência com controlador digital de sinais. 265 p. Tese (Doutorado em Engenharia Química) - Programa de Pós-graduação em Engenharia Química - Universidade Estadual de Maringá. Maringá, 2012.

SNATURAL., Tratamento da água com ozônio. Disponível em: <http://www.snatural.com.br/Tratamento-Agua-Ozonio.html> Acessado em: 05/08/2013.

SOUZA J. B. d.. Avaliação de métodos para desinfecção de água, empregando cloro, ácido peracético, ozônio e o processo de desinfecção combinado ozônio/cloro. São Carlos: USP,2006, Tese (Doutorado) - Escola de Engenharia de São Carlos, Universidade de São Paulo, 2006. 